\title{
Histochemistry: work in progress
}

As our subscribers have been notified in a recent letter, this issue of the European Journal of Histochemistry is the last one to be edited and printed by "Luigi Ponzio e figlio editori": They have generously collaborated with us with the greatest care and professionality for the past twenty years and for that we wish to thank Mr. Luigi Ponzio and his entire staff (in particular, Mr. Luigi Guardamagna) most hearthly.

The new publisher Tipografia PIME Editrice has assured us of a strong support in the promotion and the development of the image of the European Journal of Histochemistry in its relations with the media at all levels.

While a change in the Publisher may be seen as a merely technical one, it is also the occasion to reflect upon how a Journal such as ours can be enriched.

The Journal's topics touch upon many of the basic issues in biology and, through these, in pathology. Our subjects are humans, as well as all animals and plants, not only looked upon as objects for comparison and taxonomic analysis, but also as models for detailed study of the specific behaviours of animal and plant cells during development, under normal and pathological conditions.

Over the past forty years, Histochemistry has first been an attendant technique of biochemistry and morphology, with the aim of "seeing" a certain chemically-defined substance in a tissue; it has then become a focal point for integrating morphological, biophysical, biolochemical, and molecular methodologies in situ and extra situm, towards a unitary reflection of biology.

A very interesting definition of the word Histochemistry in the 80's from a researcher's point of view, can be found in the words of John Scott, in his article in memoriam of David Glick (2000): "Our targets were the chemical untested speculations of eminent ultrastructuralists who followed the line, then popular, that if a tissue element contains substance $\mathrm{X}$ and your reagent stained the tissue element, then it was specific for $X$. This very imperfect logic was anathema to him (David
Glick) and he worked relentlessly to introduce 'hard science' into histochemical measurements".

Even only a perfunctory glance at the topics of the European Journal of Histochemistry over the last years will attest the effort to go towards this 'hard science' as suggested by Glick, owing to the fact that it accepts papers on arguments even very different from each other, provided that they deal with themes central to biology, as it is developing in the new millenium.

Some few references may illustrate this.

The first example concerns the role of lipids in the nucleus (see also my editorial, Manfredi Romanini, 2000). A symposium coordinated by A.F. Manzoli (2000) on the nuclear lipid signalling system was a very successful one; interesting data coming out of those five lectures stimulated much, and sometimes even heated, discussion so that Manzoli was able to conclude: "The reviews collected in this issue will certainly clarify a number of aspects, even though it could happen that sometimes more questions than answers will be provided and this is, in a scientific field in continuous progress, the most exciting new". The first article by Cocco et al. (2000) draws a definition of the intranuclear signalling system which uses the phosphoinositide pathway for the control of cell proliferation and differentiation. The second one, by D'Santos et al. (2000), dealt with second messengers (as they are called by Manzoli), i.e. the nuclear inositides and the whole system of the phosphatidylinositol phosphates regulating them. These signalling systems are then described by Capitani et al. (2000) in a model of granulocyte differentiation. Raben et al. (2000) studied with great attention the specific role of the signal transduction cascade in the nuclear envelope: at this level, they confirmed the existence of signals of the transduction cascade, analysing at least three types of molecules involved in these cascades: protein kinases, lipid metabolites, GTPases (these molecules could be an extension of the transduction system located in the cell 
membrane). In the last paper, Maraldi et al. (2000) demonstrated the involvement of nuclear inositides in the modulation of essential nuclear functons, such as chromatin remodelling and transcript splicing.

I mentioned earlier the great variability of the topics, which is a characteristic of the European Journal of Histochemistry. I would now like to illustrate our proposal to give special attention to plant cell biology. This matter had interested us in the past, but now we are pressed to take it up again owing to the interest elicited by the minireview of Medina et al. (2000) on the functional organization of the nucleolus in proliferating plant cells.

Concluding my 2001 editorial article, I invited the botanists to find in our Journal a forum for a discussion of the recent ideas and innovations (methods and contents) that are animating the research in their discipline. Carbonera et al. (2001), introducing a series of five original papers in volume 45 , each one representing a very different approach in plant biology, emphasized how the use of the modern histochemical techniques, i.e. flow cytometry and hybridization methods, may provide insights in particular fields of plant biology. Thus, in the first two papers, both by Lingua et al. (2001 a,b), the reaction of the nucleus in roots cells with arbuscular micorrhyzal fungi or with phytoplasma pathogens was studied: in the former interaction, nuclear hypertrophy, loosening of chromatin structure and an increase in the amount of DNA were seen; in the latter, the interaction with pathogens produced an opposite effect on the nuclear organization, lowering the DNA quantity and causing chromatolysis. In the paper by Balestrazzi et al. (2001), the spatial intranuclear distribution of the transcripts, derived from the expression of top 1 genes coding for the alfa and beta isoforms of DNA topoisomerase 1, was evaluated in two cell systems from Daucus dacota, i.e. hypocotyls and somatic embryo cell populations, which are differently involved in the proliferation process; the methods were hybridization using radio-labelled specific probes and non-radioisotopic, digoxigenin-labelling. There is also a technical interest in this approach, because it succeeded in discriminating between the role of top 1 gene during cell proliferation and differentiation. It confirms that gene expression and cell proliferation are strongly correlated, although there is evidence neither for a periodicity of top 1 expression throughout the cell cycle, nor for a spatial difference in the mode of the expression.

In the physical interaction between the arbuscular mycorrhyzal fungi and the naturally occurring and genetically modified bacterial biofertilizers and biopesticides of the plant growth (promoting rhizobacteria), Bianciotto et al. (2001) used confocal and electron microscopy for demostrating in situ the involvement of polysaccharides in the attachment fibers; their results can open important applications in biotechnology.

The last paper of this series of representative models of modern plant biology shows an interesting double histotopochemical approach to the problem of localizing cellulose in some algal cell groups (Baldan et al., 2001). The ultrastructural techniques provide a comparison between the pictures obtained with a classical reagent for polysaccharides (the periodic acid thiosemicarbazide-silver proteinate), and an enzyme-gold labelling test, where the cellulase-enzyme complex is used as a marker of the intratissutal distribution of cellulose. The map of its localisation in different algal tissues differentiate the red, brown and green algae and the authors emphasize that the new cellulase-gold represents a significant improvement in this research field.

This opening to plant biology was so successful that, in volume 46 , four other good papers have been published (Tagu et al. 2002; Acevedo et al. 2002; Lanfranco et al. 2002; Scialabba et al. 2002), which showed the vitality of the interaction between the new histochemistry and basic biology of plants.

Over the last years, basic cell biology has been fascinated with the intriguing process of programmed death in animals and plants, which is more and more becoming a challenge for histochemical investigation. This complex problem, and especiallly that of the clearance of apoptotic cells, was the object of studies summarized in many elegant reviews (see, for instance, Henson, 2001; Chimini, 2002). In volume 44 of the European Journal of Histochemistry, a minireview by L. Dini (2000) appeared vith the winning title "Recognizing death: liver phagocytosis of apoptotic cells": here, the phenomenon of apoptosis is analysed in a significant biologic scenario, i.e. the context of the liver parencchima in vivo. In the same issue another minireview by Rovere et al. 
(2000) was specifically concerned with the problem of how to dispose of apoptotic cells in vivo: "the dendritic cells connection" refers to phagocytosis of apoptoses by antigen-presenting cells, which enable the immune system to remove cell corpses through mechanisms suitable to maintain tolerance. This paper introduced the problem of the control of the autoimmune response, which is so important in the pathogenesis of some diseases. Other papers analyze the conditions of apoptosis more specifically, through electron microscopy and cytometry (Bonanno et al., 2000; Pellicciari et al., 2000; Spano et al., 2000; Soldani et al., 2001). Along this line I would like to remind the reader of the minireview by Steinbeck (2001), where disturbances in the apoptotic process are mentioned among the pathologies of mitosis producing altered proliferation and leading to deviations toward cancer. In volume 46 , four papers dealt with this same problem: Cappello et al. (2002), which refers to some systems of dysregulation; Uva et al. (2002), describing microgravity-induced apoptosis; Avallone et al. (2002) studying, by TEM and TUNEL techniques, the role of apoptosis during lung development in the chick embryo; finally, the paper by Bonanno et al. (2002) dealt with the sinchronization between alterations in the nucleus and the cell membrane during the apoptotic process.

The problem of DNA instability and its possible meaning as a marker of malignancy has been repeatedly discussed on the European Journal of Histochemistry during the last couple of years. The most recent papers on subject were by Steinbeck and Auer (2000), Khaled et al. (2000), Iwasa e al. (2001), Hirai et al. (2001): these papers, through typical histochemical markers, approached the problem of finding new diagnostic tools for the precocious detection of tumor cells.

Finally, I would like to give an example of the traditional taxonomic and naturalistic interests of our Journal, which is proud to publish researches at all levels of the living beings. Besides human and laboratory animals, height vertebrate non-mammalian species, three invertebrate species and twenty plant species have been considered in the papers published in 2001 only. This evidence should remind our authors and readers (immunologists, oncologists, pathologists, microbiologists, zoologists, botanists) that the field of interest of the European Journal of Histochemistry is opened to all researchers who study life at all levels, in the great nature scenario, in order to get models useful for more and more sophisticated and informative comparisons.

In the year to come, the European Journal of Histochemistry will try to proceed along this line. Several of the forthcoming papers will actually deal with hot topics in cell biology (such as stem cell characteristics, nuclear reprogramming of differentiated cells, remodelling of nuclear organization during early embryogenesis) and we believe that our Journal will continue to be a forum where all the ideas for a new histochemistry may truely develop.

M.G. Manfredi Romanini

\section{REFERENCES}

Acevedo R., Cuadrado A., De la Torre C., and Moreno Díaz de la Espina S.: Behaviour of ribosomal genes and nucleolar domains during activation of root primordia in sugarcane (Saccharum officinarum L.). From unsoaked quiescence to steady state of proliferation. Eur. J. Histochem. 46, 143-158, 2002.

Avallone B., Balsamo G., Trapani S., Marmo F.: Apoptosis during chick inner ear development: some observations by TEM and TUNEL techniques. Eur. J. Histochem. 46, 53-59, 2002.

Baldan B., Andolfo P., Navazio L., Tolomio C., Mariani P.: Cellulose in algal cell wall : an "in situ" localization. Eur. J. Histochem. 45, 51-56, 2001

Balestrazzi A., Bernacchia G., Pitto L., Luccarini G. and Carbonera D.: Spatial expression of DNA topoisomerase I genes during cell proliferation in Daucus carota. Eur. J. Histochem. 45, 31-38, 2001

Bianciotto V., Andreotti S., Balestrini R., Bonfante P. and Perotto S.: Extracellular polysaccharides are involved in the attachment of Azospirillum brasilense and Rhizobium leguminosarum to arbuscular mycorrhizal structures. Eur. J. Histochem. 45, 39-50, 2001.

Bonanno E., Ruzittu M., Carlà E.C., Montinari M.R., Pagliara P. and Dini L.: Cell shape and organelles modifications in apoptotic U937 cells. Eur. J. Histochem. 44, 237-246, 2000.

Bonanno E., Tagliafierro G., Carlà E.C., Montinari M.R., Pagliara P., Mascetti G., Spagnoli L.G., Dini L.: Syhronized onset of nuclear and cell surface modifications in U937 cells during apoptosis. Eur. J. Histochem. 46, 61-74, 2002.

Capitani S., Marchisio M., Neri L.M., Brugnoli F., Gonelli A., and Bertagnolo V.: Phosphoinositide 3-kinase is associated to the nucleus of HL-60 cells and is involved in their ATRA-induced granulocytic differentiation. Eur. J. Histochem. 44, 61-66, 2000. 
Cappello: Defective apoptosis and its meaning in tumorigenesis. Eur. J. Histochem. 46, 199-208, 2002.

Carbonera D., Berta G., and Bonfante P.: Histochemistry for plant biology. Eur. J. Histochem. 45, 7-8, 2001.

Chimini G.: Repulsive encounters. Nature 416, 139-141, 2002.

Cocco L., Rhee S.G., Gilmour R.S., and Manzoli F.A.: Inositide-specific phospholipase $\mathrm{C}$ signalling in the nucleus. Eur. J. Histochem. 44, 45-50, 2000

Dini L.: Recognizing death: liver phagocytosis of apoptotic cells. Eur. J. Histochem. 44, 217-228, 2000.

D’Santos C., Clarke J.H., Roefs M., Halstead J.R., and Divecha N.: Nuclear inositides.: Eur. J. Histochem. 44, 51-60, 2000.

Henson P.: Apoptotic cell removal. Curr. Biol. 19, 795-805, 2001.

Hirai K., Kumakiri M., Ueda K., Imamura Y., Noriki S., Nishi Y., Kato H., and Fukuda M.: Clonal evolution and progression of 20-methylcholanthrene-induced squamous cell carcinoma of mouse epidermis as revealed by DNA instability and other malignancy markers. Eur. J. Histochem. 45, 319-332, 2001.

Iwasa M., Imamura Y., Noriki S., Nishi Y., Kato H., and Fukuda M.: Immunohistochemical detection of early-stage carcinogenesis of oral leukoplakia by increased DNA-instability and various malignancy markers. Eur. J. Histochem. 45, 333346, 2001.

Khaled A., Imamura Y., Noriki S., and Fukuda M.: Early progression stage of malignancy of uterine cervical dysplasia as revealed by immunohistochemical demonstration of increased DNA-instability. Eur. J. Histochem. 44, 143- 156, 2000.

Lanfranco L., Balsamo R., Martino E., Perotto S., and Bonfante P.: Zinc ions alter morphology and chitin deposition in an ericoid fungus. Eur. J. Histochem. 46, 341-350, 2002.

Lingua G., D'Agostino A., Fusconi A., and Berta G.: The nucleus of differentiated root plant cells: modifications induced by arbuscular mycorrhizal fungi. Eur. J. Histochem. 45, 21-30, 2001

Lingua G., Fusconi A., and Berta G.: Nuclear changes in pathogen-infected tomato roots. Eur. J. Histochem. 45, 9-20, 2001

Manfredi Romanini M.G.: Editorial, Eur. J. Histochem. 44, 56, 2000.

Manfredi Romanini M.G.: The year of encroaching genomics, Eur. J. Histochem. 45, 5-6, 2001

Manzoli F.A.; Nuclear Lipid Signalling Symposium: Eur. J. Histochem. 44, 43-44, 2000.

Maraldi N.M., Zini N., Santi S., and Manzoli F.A.: Intranuclear domains involved in inositol lipid signal transduction. Eur. J. Histochem. 44, 81-88, 2000.

Medina F.J., Cerdido A., and de Carcer G.: The functional organization of the nucleolus in proliferating plant cells. Eur. J. Histochem. 44, 117-132, 2000
Pellicciari C., Bottone M.G., Scovassi A.I., Martin T.E., and Biggiogera M.: Rearrangement of nuclear ribonucleoproteins and extrusion of nucleolus-like bodies during apoptosis induced by hypertonic stress. Eur. J. Histochem. 44, 247-254, 2000

Raben D.M., and Baldassare J.J.: Nuclear envelope signaling-role of phospholipid metabolism. Eur. J. Histochem. 44, 67-80, 2000.

Rovere P., Fazzini F., Sabbadini M.G., and Manfredi A.A.: Apoptosis and systemic autoimmunity: the dendritic cell connection. Eur. J. Histochem. 44, 229-236, 2000.

Scialabba A., Bellani L.M., and Dell'Aquila A.: Effects of ageing on peroxidase activity and localization in radish (Raphanus sativus L.) seeds. Eur. J. Histochem. 46, 351-358, 2002.

Scott J.: Obituary: David Glick. Eur. J. Histochem. 44, 205 , 2000

Soldani C., Bottone M.G., Pellicciari C., and Scovassi A.I. Two-color fluorescence detection of Poly (ADP-Ribose) Polymerase-1 (PARP-1) cleavage and DNA strand breaks in etoposide-induced apoptotic cells. Eur. J. Histochem. 45 , 389-392, 2000

Spano A., Sciola L., Monaco G., and Barni S.: Relationship between actin microfilaments and plasma membrane changes during apoptosis of neoplastic cell lines in different culture conditions. Eur. J. Histochem. 44, 255-268, 2000

Steinbeck R.G., and Auer G.U.: Genome instability in human tumorigenesis: microphotometry of interphase nuclei and pathologic mitoses reveals dysplasia. Eur. J. Histochem. 45 , $311-318,2000$

Steinbeck R.G.: Pathologic mitoses and pathology of mitosis in tumorigenesis. Eur. J. Histochem. 45, 311-318, 2001

Tagu D., Marmeisse R., Baillet Y., Rivière S., Palin B.,•Bernardini F., Méreau A., Gay G., Balestrini R., Bonfante P., and Martin F.: Hydrophobins in ectomycorrhizas: heterologous transcription of the PisolithusHydPt-1 gene in yeast and Hebeloma cylindrosporum. Eur. J. Histochem. 46, 23-29, 2002.

Uva B.M., Masini M.A., Sturla M., Bruzzone F., Giuliani M., Tagliafierro G., and Strollo F.: Microgravity-induced apoptosis in cultured glial cells. Eur. J. Histochem. 46, 209-215, 2002. 